IP Periodica Polytechnica

Chemical Engineering

58(2), pp. 165-169, 2014

DOI: 10.3311/PPch.7303

Creative Commons Attribution (i)

RESEARCH ARTICLE

\section{Integrated Production of}

$y$-butyrolactone through Coupling of

Maleic Anhydride Hydrogenation and

1,4-butanediol Dehydrogenation

\author{
Ahtesham Javaid ${ }^{1 *} /$ Costin Sorin Bildea ${ }^{1}$
}

RECEIVED 26 January 2014; ACCEPted AfTER REVISIOn 24 April 2014

\section{Abstract}

Design and plantwide control of an integrated plant for the hydrogenation of maleic anhydride and the dehydrogenation of 1,4-butanediol has been studied for the synthesis of $\gamma$-butyrolactone in an adiabatic reactor, under different conditions of reaction temperatures and hydrogen to feed ratio, realizing optimal hydrogen utilization and better energy efficiency. Compared to stand-alone processes, the integrated process has several advantages, e.g., easy temperature control, improved $\gamma$-butyrolactone yield, good energy efficiency and optimal hydrogen utilization. The stability and robustness of the process is checked by rigorous dynamic simulation in AspenDynamics.

\section{Keywords \\ Reaction coupling ' Dehydrogenation ' $\gamma$-butyrolactone * Hydrogenation $\cdot$ Plantwide control}

\section{Introduction}

$\gamma$-butyrolactone (GBL) is known as a versatile solvent and a raw material for the synthesis of pyrrolidone, N-methyl pyrrolidone, N-vinyl pyrrolidone, herbicides, and rubber additives. GBL is manufactured via two methods: hydrogenation of maleic anhydride (MA) and dehydrogenative cyclization of 1,4-butanediol (BDO). Both processes are typically performed in multi-tubular fixed-bed reactors [1]. The catalytic hydrogenation of MA or its derivatives such as maleic acid, succinic anhydride or succinic maleate to GBL has been reported in the literature [2]. The reaction equation of MA hydrogenation to GBL can be represented as follows:

$$
\mathrm{C}_{4} \mathrm{H}_{2} \mathrm{O}_{3}+3 \mathrm{H}_{2} \rightarrow \mathrm{C}_{4} \mathrm{H}_{6} \mathrm{O}_{2}+\mathrm{H}_{2} \mathrm{O}
$$

It is obvious from Eq. 1 that production of $1 \mathrm{~mol} \mathrm{GBL}$ requires $1 \mathrm{~mol} \mathrm{MA}$ and $3 \mathrm{~mol} \mathrm{H}_{2}$, releasing $211 \mathrm{~kJ}$ of heat. Owing to the strong exothermic nature of the reaction, the temperature of the process is difficult to be controlled. In a tubular fixed bed reactor, this might cause thermal run-away, lead to apparent hotspots and low selectivity to the desired product, GBL. A large amount of supply hydrogen is needed.

The vapor phase catalytic dehydrogenation of $\mathrm{BDO}$ to GBL has also been described in the literature [3]. This reaction can be expressed as follows:

$$
\mathrm{C}_{4} \mathrm{H}_{10} \mathrm{O}_{2} \rightarrow \mathrm{C}_{4} \mathrm{H}_{6} \mathrm{O}_{2}+2 \mathrm{H}_{2}
$$

From Eq. 2 it is evident that production of $1 \mathrm{~mol} \mathrm{GBL}$ requires $1 \mathrm{~mol} \mathrm{BDO}$, releasing $2 \mathrm{~mol} \mathrm{H}_{2}$ and requiring $61.6 \mathrm{~kJ}$ of heat. The hydrogen released from reaction cannot be used properly in a single dehydrogenation process.

The new catalytic process combines both reactions into one coupled system which can significantly improve the yield of the catalytic hydrogenation of MA, apart from the better thermal balance and the effective usage of hydrogen through hydrogen transfer between the two reactants. In addition, this new integrated process produces one desired product (GBL)
Politehnica of Bucharest, Str. Gh. Polizu 1, 011061, Bucharest, Romania

*Corresponding author, e-mail: a_javaid@chim.upb.ro 
with a substantially increased hydrogenation yield. The new combined reaction can be expressed as follows:

$$
\mathrm{C}_{4} \mathrm{H}_{2} \mathrm{O}_{3}+1.5 \mathrm{C}_{4} \mathrm{H}_{10} \mathrm{O}_{2} \rightarrow 2.5 \mathrm{C}_{4} \mathrm{H}_{6} \mathrm{O}_{2}+\mathrm{H}_{2} \mathrm{O}
$$

The MA to BDO ratio used in the process is $1: 1.5$ to balance the hydrogen consumed and produced in the system. Due to this perfect hydrogen balance, better control of the reactor temperature is expected, as less heat is released as compared to individual MA hydrogenation. The combined system for hydrogenation of MA and the dehydrogenation of BDO could be carried out over the same $\mathrm{Cu}$-based catalyst, and under similar reaction conditions. From Eq. 3 it can be noted that $2.5 \mathrm{~mol}$ of GBL requires $1 \mathrm{~mol}$ of $\mathrm{MA}$ and $1.5 \mathrm{~mol}$ of $\mathrm{BDO}$. The reaction kinetics used for the simulations assumes first-order reaction rate, due to high hydrogen excess. The kinetic parameters on $\mathrm{Cu}-\mathrm{Zn}-\mathrm{Al}$ catalyst are extracted from the literature:

Maleic anhydride hydrogenation [4]:

$$
k_{1}=2.57 \times 10^{17} \cdot \exp (-262 / T) \quad\left(\mathrm{kmol} \mathrm{m}^{-3} \mathrm{~s}^{-1} \mathrm{~Pa}^{-1}\right)
$$

\section{1, 4-butanediol dehydrogenation [5]:}

$$
k_{1}=4.57 \times 10^{17} \cdot \exp (-5800 / T) \quad\left(\mathrm{kmol} \mathrm{m} \mathrm{m}^{-3} \mathrm{~s}^{-1} \mathrm{~Pa}^{-1}\right)
$$

The coupling can be performed at reaction temperature $30-50^{\circ} \mathrm{C}$ less as compared to individual ones, because the rich active hydrogen species on the catalyst surface from BDO dehydrogenation promotes the MA hydrogenation reaction [6, 7]. The coupling may lead to advantages, such as good energy efficiency, the easy temperature control in an adiabatic reactor due to moderate heat release compared with the single reaction processes which can avoid the formation of apparent hotspots or cold spots $[6,7]$. The researchers in their studies $[6,7]$ have worked for the possibility of coupling these reactions taking into account only the stand-alone reactor.

In this paper, we report for the first time an integrated process for $\gamma$-butyrolactone (GBL) from 1,4-butanediol (BDO) and maleic anhydride (MA). The advantages of hydrogen utilization, reduced parametric sensitivity and safer operation are emphasized. In our study the behavior of coupled process is studied in the whole plant using AspenPlus and AspenDynamics software, in steady as well as in dynamic state.

\section{Integrated Process}

This section presents a process which couples dehydrogenation of 1,4-butanediol and hydrogenation of maleic anhydride in a single adiabatic reactor. The benefit of coupling the exothermic hydrogenation and endothermic dehydrogenation reactions is that the heat generated by the first reaction is taken up by the second one, and no additional heating or cooling arrangements are required in the system. This leads to a much simpler reactor and the parametric sensitivity of the reactor is greatly reduced. The conversion of both maleic anhydride and 1,4-butanediol is $>99.5 \%$, eliminating recycling of reactants. Figure 1 presents the flowsheet of the integrated maleic anhydride hydrogenation and 1,4- butanediol dehydrogenation process. Reactants (MA $20 \mathrm{kmol} / \mathrm{h}, \mathrm{BDO}-30 \mathrm{kmol} / \mathrm{h}$ and hydrogen $-5000 \mathrm{kmol} / \mathrm{h}$ ) are

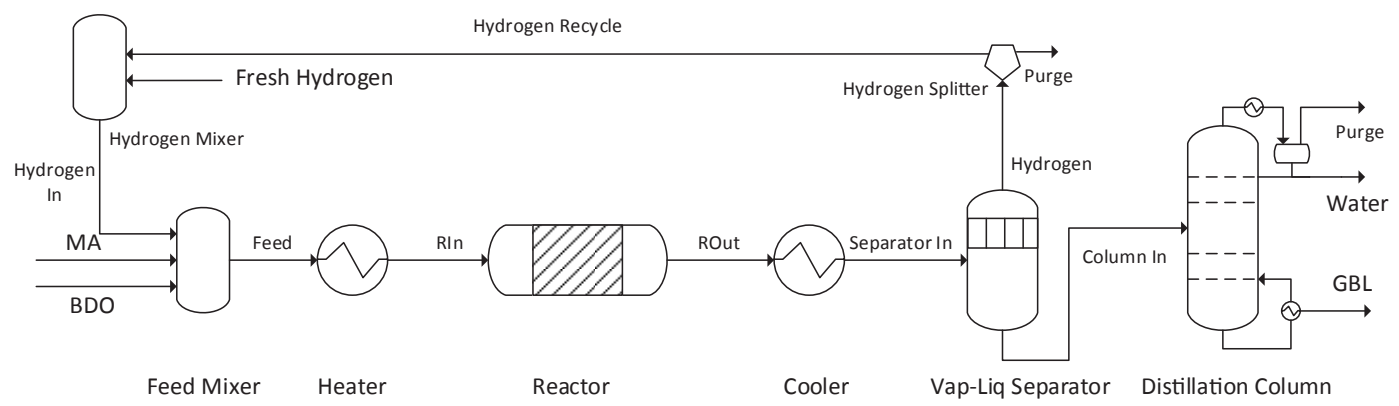

Fig. 1. Integrated Plant
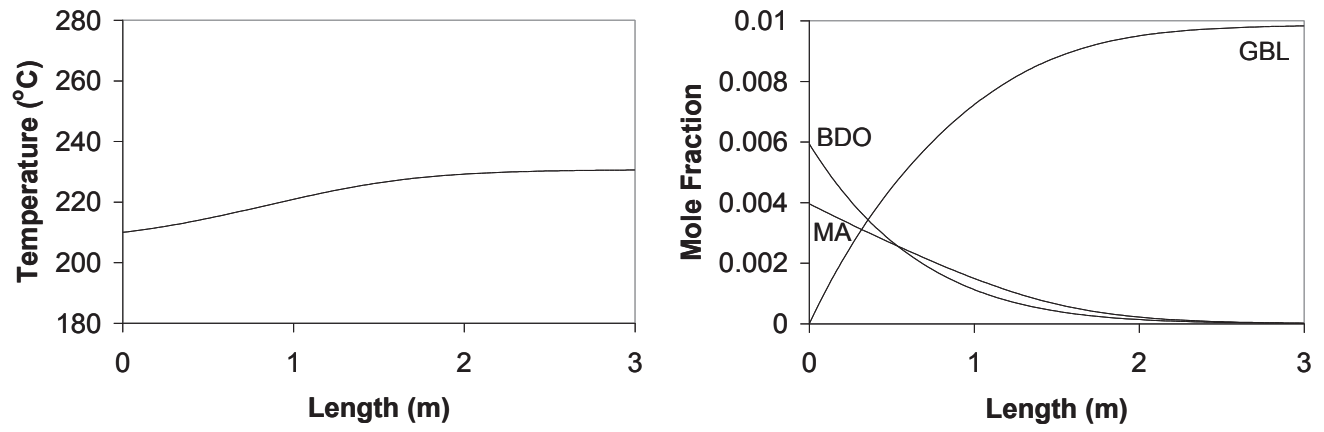

Fig. 2. Temperature (a) and Molar Fraction (b) Profiles along the Integrated Reactor 
Tab. 1. Stream Table

\begin{tabular}{|c|c|c|c|c|c|c|c|}
\hline & MA & BDO & GBL & H2REC & RIN & ROUT & WATER \\
\hline Pressure (bar) & 1.5 & 1.5 & 1.2 & 1.2 & 1.5 & 1.5 & 1.2 \\
\hline Vapor Fraction & 0 & 0 & 0 & 1 & 1 & 1 & 0.001 \\
\hline Mole Flow (kmol/hr) & 20 & 30 & 49.62 & 4548 & 5098 & 5118 & 14.94 \\
\hline Hydrogen & 0 & 0 & 0 & 0.989 & 0.981 & 0.977 & 0.001 \\
\hline Water & 0 & 0 & 0 & 0.01 & 0.009 & 0.013 & 0.984 \\
\hline Maleic Anhydride & 1 & 0 & 0 & 0 & 0.004 & 0 & 0.007 \\
\hline$\gamma$-butyrolactone & 0 & 0 & 1 & 0 & 0 & 0.01 & 0.003 \\
\hline
\end{tabular}

mixed and brought to reaction temperature $\left(210^{\circ} \mathrm{C}\right)$. The reactions take place in a reactor ( $5 \mathrm{~m}$ diameter, $3 \mathrm{~m}$ length) which is adiabatically operated. The reactor is designed for the total conversion of reactants.

Figure 2 shows mole fraction and temperature profiles along the reactor. The conversion of reactants into products is uniformly distributed with the reactor length and almost constant temperature should be remarked.

The reactor outlet is cooled to $20^{\circ} \mathrm{C}$, and vapor-liquid separation is performed. As the complete conversion ( $>99.5 \%)$ of reactants is achieved, there is no recycling of reactants simplifying technical difficulties. A high boiling point difference between water and GBL results in easier separation by distillation. GBL is obtained as a product at the rate of $49.6 \mathrm{kmol} / \mathrm{h}$ with high purity $>99 \%$. In theory, the plant is best operated at $\mathrm{MA}: \mathrm{BDO}=1: 1.5$ with very high ratio of hydrogen: feed = 100:1 to 200:1. Perfect balancing of hydrogen consumption / generation in the two reactions is impossible in practice. Therefore, a small amount of fresh and purge hydrogen streams are provided for better control purposes. Stream table of the process is given as Table 1.

\section{Sensitivity Analysis}

The chemical reactor deserves a special discussion. To remove the risk of run-away in hydrogenation of maleic anhydride as an individual process a large excess of hydrogen to feed ratio $(100-200: 1)$ is provided to the system. Despite this, the reaction is very difficult to control. The integrated reactor is thus operated at various process conditions to emphasize the stability of reactor with reduced parametric sensitivity.

First the effect of feed temperature is analyzed by fixing hydrogen to feed ratio 100:1. The results at the reactor outlet are tabulated in Table 2 while temperature and mole fraction profiles are shown in Figure 3. The reactants conversion and temperature difference in reactor increased on increasing feed temperature.

Similarly the effect of changing the hydrogen to feed ratio is studied by keeping the feed temperature constant at $210^{\circ} \mathrm{C}$.
The reactor outlet conditions are tabulated in Table 3, while temperature and mole fraction profiles are shown in Figure 4. The reaction proceeds smoothly on increased hydrogen to feed ratio and the temperature increase in the reactor become smaller. Maintaining temperature difference at minimum level becomes vital in case when the catalyst is sensitive to temperature.

Tab. 2. Effect of Feed Temperature

\begin{tabular}{ccccc}
\hline \multirow{2}{*}{ Feed Temperature $\left({ }^{\circ} \mathrm{C}\right)$} & \multirow{2}{*}{$\Delta \mathrm{T}\left({ }^{\circ} \mathrm{C}\right)$} & \multicolumn{3}{c}{ Molar Flow (kmol/hr) } \\
\cline { 3 - 5 } & & $\mathrm{MA}$ & $\mathrm{BDO}$ & $\mathrm{GBL}$ \\
\hline 200 & 15 & 3.753 & 0.510 & 45.74 \\
210 & 20 & 0.095 & 0.071 & 49.835 \\
220 & 22 & $<0.001$ & 0.009 & 49.991 \\
\hline
\end{tabular}

Tab. 3. Effect of Hydrogen to Feed Ratio

\begin{tabular}{ccccc}
\hline \multirow{2}{*}{$\left(\mathrm{H}_{2}\right.$ : Feed $)$} & \multirow{2}{*}{$\boldsymbol{\Delta}\left({ }^{\circ} \mathrm{C}\right)$} & \multicolumn{3}{c}{ Molar Flow $(\mathrm{kmol} / \mathrm{hr})$} \\
\cline { 3 - 5 } & & $\mathrm{MA}$ & $\mathrm{BDO}$ & $\mathrm{GBL}$ \\
\hline $80: 1$ & 25 & 0.014 & 0.037 & 49.949 \\
$100: 1$ & 20 & 0.095 & 0.071 & 49.835 \\
$120: 1$ & 17 & 0.229 & 0.091 & 49.680 \\
\hline
\end{tabular}

\section{Plantwide Dynamics and Control}

Dynamic simulation is a convenient method for analyzing the performance of process control system. The dynamics of the plant must be considered in order to prove the stability of the operating point and the resiliency with respect to disturbances. The main task of plantwide control system is controlling the inventory of reactants, products and impurities. A dynamic model of the plant is built in AspenDynamics, and the flexibility in manipulating the inlet flow rates is investigated. The plant wide control system shown in Figure 5, fixes the flow rate of maleic anhydride, 1,4-butanediol and hydrogen at reactor inlet to eliminate any undesired multiplicity. Control of heat exchangers, two phase separator and distillation column 

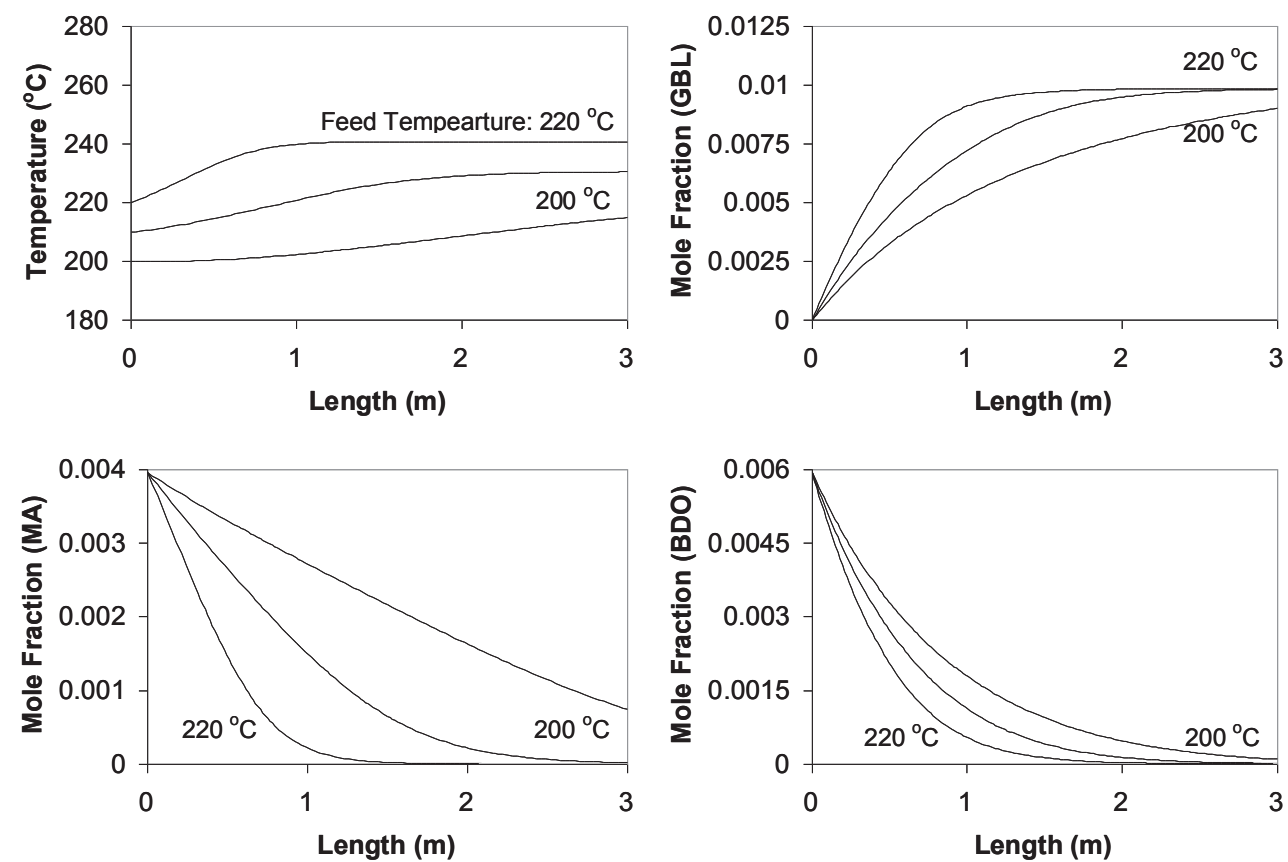

Fig. 3. Effect of Feed Temperature
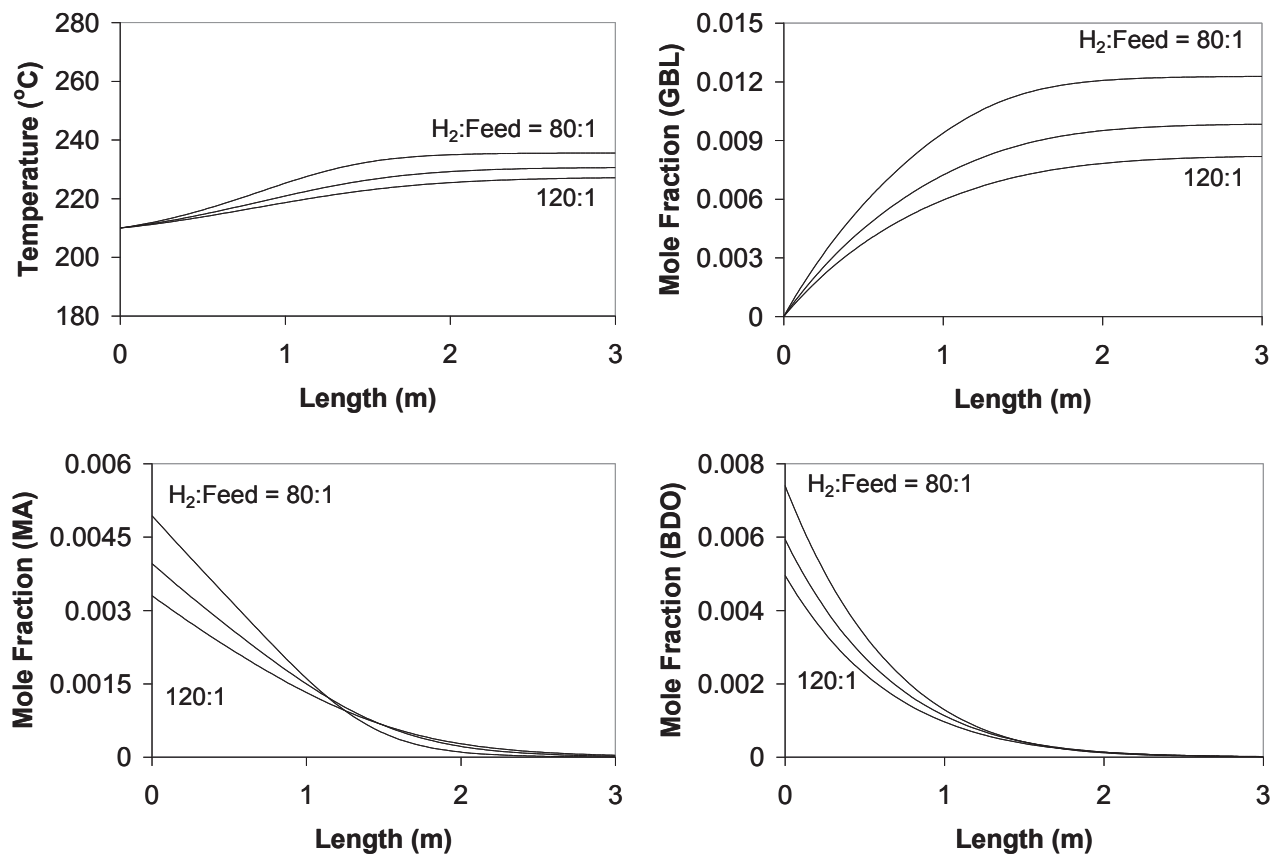

Fig. 4. Effect of Hydrogen to Feed Ratio

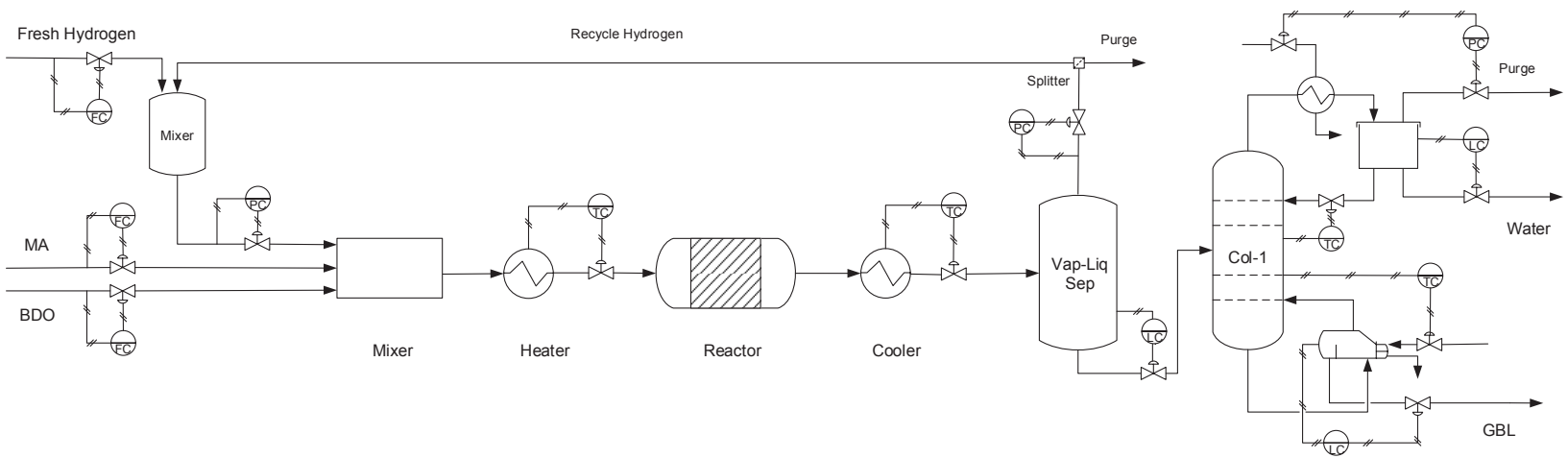

Fig. 5. Control Scheme of Integrated Plant 
is standard. The gain of the temperature, pressure and liquid level controllers was set to 1,20 and $10 \% / \%$, respectively. For pressure and temperature control, the reset time was similar to the process time constants, namely $12 \mathrm{~min}$ and $20 \mathrm{~min}$, respectively. For the level controllers, a large reset time (60 min) is chosen as no tight control is required.

The effect of changing the inlet flows on product purity, production and recycle rates are plotted in Figure 6.

Starting from steady state, both MA and BDO feeds were increased by $10 \%$ at $\mathrm{t}=1 \mathrm{hr}$. Then, at $\mathrm{t}=10 \mathrm{hr}$ the feed rates were reset to initial value $(\mathrm{t}=10 \mathrm{hr})$, further decreased by $10 \%$ $(\mathrm{t}=20 \mathrm{hr})$ and then brought back to the initial value $(\mathrm{t}=32 \mathrm{hr})$. The change in feed rate is followed by change in GBL production rate, while purity remains high. The plant can withstand the combined disturbances of the feed and achieves stable operation.

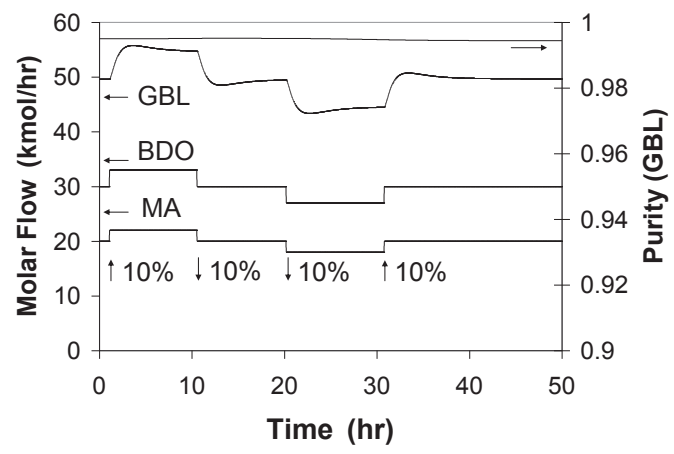

Fig. 6. Dynamic Simulation

\section{References}

1 Kirk R. E., Othmer F., Kroschwitz J. I., Howe-Grant M., KirkOthmer's Encyclopedia of Chemical Technology. John Wiley \& Sons, (1991).

2 Bergfeld M. J., Uihlein K., Process for the preparation of gammabutyrolactone and the use thereof,. U.S. Patent, 6075153, (2000).

3 Tatsumi I., Kenji K., Sadakatsu S., Hiroshi U., Process for the preparation of gamma-butyrolactone, Eur. Patenet, EP584408, (1994).

4 Ichikawa N., Sato S., Takahashi R., Sodesawa T., Inui K., Dehydrogenative cyclization of 1,4-butanediol over copper-based catalyst. Journal of Molecular Catalysis A: Chemical, 212 (1-2), pp. 197-203, (2004).

DOI: $10.1016 /$ j.molcata.2003.10.028

5 Zhao G. W., Zhu Y. L., Teng B. T., Zheng H. Y., Xiang H. W., Li Y. W, Kinetics Study on Maleic Anhydride Gas-Phase Hydrogenation to $\gamma$-Butyrolactone. Journal of Chemical Engineering of Chinese Universities, 20 (5), pp. 740-744, (2006).
It should be remarked that controllability could be also assessed by linearizing the dynamic model around the nominal operating point and analyzing the properties of the linear model. Tools as Relative Gain Array (RGA), Singular Value Decomposition, Morari Resilience Index, Condition Numbers and Niederlinski index [8] give useful information about loop interaction in decentralized control, sensitivity to implementation errors, effectiveness of the manipulated variables and feasible input-output pairing. However, a linear model of the complete plant is difficult to obtain and the extremely large dimension of the state space ( $\sim 10000$ variables) makes all numerical calculations ill-conditioned requiring application of model reduction techniques. Moreover, although RGA is useful for discarding poor decentralized pairings, it is not recommended as an effective tool for recommending good pairings because interactions between control loops is not necessarily bad for disturbance rejection [9]. Therefore, the rigorous dynamic simulation is the decisive controllability test [10].

\section{Conclusions}

The coupling of exothermic maleic anhydride hydrogenation with the endothermic 1,4- butanediol dehydrogenation is possible. High GBL purity and raw materials conversion exceeding 99\% can be achieved. The safe operation of the chemical reactor should be remarked. The plant is controllable, allowing for changes in production rate while keeping high product purity. Based on the results, the integration of this process on the basis of balancing heat in the system will be of interest.

6 Zhu Y. L., Xiang H. W., Wu G. S., Bai L., Li Y. W., A novel route for synthesis of $\gamma$-butyrolactone through the coupling of hydrogenation and dehydrogenation. Chemical Communication, pp. 254-255, (2002). DOI: $10.1039 / B 109658 \mathrm{~N}$

7 Zhu Y. L., Yang J., Dong G. Q., Zheng H. Y., Zhang H. H., Xiang H. W., Li Y. W., An environmentally benign route to $\gamma$-butyrolactone through the coupling of hydrogenation and dehydrogenation. Applied Catalysis B: Environmental, 57 (3), pp. 183-190, (2005).

DOI: $10.1016 /$ j.apcatb.2004.11.004

8 Skogestad S., Postlethwaite I., Multivariable Feedback Control: Analysis and Design, Wiley, (1996).

9 Luyben W. L., Luyben M. L., Essentials of Process Control. McGraw-Hill, (1997).

10 Dimian A. C., Bildea C. S., Chemical Process Design: ComputerAided Case Studies. Wiley-VCH, (2008). 